\title{
Survey and Research on Overseas Students' Chinese Pragmatic Competence Acquisition -With overseas students from Ningxia University as example
}

\author{
Yongqun Zhang \\ School of International Education, Ningxia University, Yinchuan, 750021, China
}

Keywords: interlanguage, pragmatic competence, pragmatic competence acquisition

\begin{abstract}
Interlanguage pragmatics is a newly-developing field in pragmatics, which is used to research the language system of second language learners from the pragmatic perspective and research pragmatic behaviors of second language learners while using second language. At present, research on interlanguage pragmatic acquisition becomes a new field of the research on second language acquisition. However, most researches in this field are related to Indo-European languages, especially English, while pragmatic competence researches on Chinese as a second language are relatively insufficient at present. In this paper, the author makes some tentative researches on pragmatic competence acquisition of Chinese as a second language from the following two perspectives: i) survey and research on overseas students' pragmatic competence acquisition for Chinese salutation; and ii) survey and research on overseas students' pragmatic competence acquisition in individual verbal behaviors.
\end{abstract}

\section{Introduction}

(I) Interlanguage pragmatics

Proposed by American psycholinguist Selinker (1972), interlanguage refers to "the dynamic language system mastered by second language learners in the learning process of second language and gradually closer to the second language with learning progress, which is different from both the first language and the target language”. The English translation of interlanguage pragmatics appeared in the early 1980s and the late 1990s. Interlanguage pragmatics is an important field involved in pragmatics. Initially, interlanguage pragmatics was developed from the research on trans-cultural pragmatics. Therefore, interlanguage pragmatics is affiliated to the research on trans-cultural pragmatics by many people. Interlanguage pragmatics is a language system involved in the research on second language learners from the pragmatic perspective, namely interlanguage system. Interlanguage pragmatics mainly includes pragmatic behaviors of second language learners while using second language. Besides, it becomes a new developing field in pragmatics.

However, the emphasis of interlanguage pragmatic research is always concentrated on differences of non- mother-tongue users' and mother tongue users' verbal behaviors in selection of strategy, linguistic form of discourse, perception of courtesy and other aspects. These researches allow us to understand characteristics of non-native-language users in language pragmatics and social pragmatics, but we have no way of understanding pragmatic knowledge acquisition and pragmatic competence development of second language learners. ${ }^{1}$ Therefore, the research on interlanguage pragmatic acquisition becomes a new filed of the research on second language acquisition at present. The former emphasizes the research on acquisition and development patterns of pragmatic competence in the learning process of second language. Specifically, it includes the following topics: how to produce and understand verbal behaviors of second language in specific context; interlanguage behavioral patterns of second language users while acquiring and using second language; interlanguage pragmatic competence of second language users while implementing second language verbal behaviors; interlanguage pragmatic analysis related to pragmatic errors of second language; communicative effects of second language; function of personality characteristics on pragmatic competence acquisition and so on. Most researches in this field are related to Indo-European languages, especially English, while pragmatic competence researches on Chinese as a second language are relatively insufficient at present. Researches in this 
field are relatively insufficient. In this paper, the author expects to make some tentative researches in this aspect.

(II) Second language communicative competence and second language pragmatic competence

The goal of second language teaching is to cultivate students' competence to use second language for communication. In September, 1988, Chinese Grading Standard and Grading Outline was published, and this standard was also officially listed in the book. At present, it is basically acknowledged in the educational circle that communicative competence includes language competence and pragmatic competence. Apparently, pragmatic competence is gradually recognized by people with communicative competence. In this paper, the relations between language competence and pragmatic competence are figured out first. Then, a discussion is made to pragmatic competence and pragmatic competence acquisition of Chinese as a second language. "Communicative competence" was proposed by sociolinguist and applied linguist Dell Hymes in his homonymic paper in 1972. This concept includes both mastering of linguistic form and understanding of sociocultural factors closely correlated with use of language. According to Dell Hymes, "language competence" is only a constituent part of "communicative competence". Acquisition of language competence refers to both acquisition of knowledge about language rules and acquisition of rules for use of language in social communication ${ }^{[2]}$. We think that the former refers to "language competence" and the latter to "pragmatic competence". Communicative competence doesn't mean simple language competence plus pragmatic competence. Instead, it is a sort of expression to integrative competence to freely and appropriately express one's thoughts, views and emotions in the natural environment (Jiang Liping, 2007). ${ }^{(2)}$ Professor Jiang describes the relations between communicative competence, language competence, pragmatic competence and integrative competence as follows:

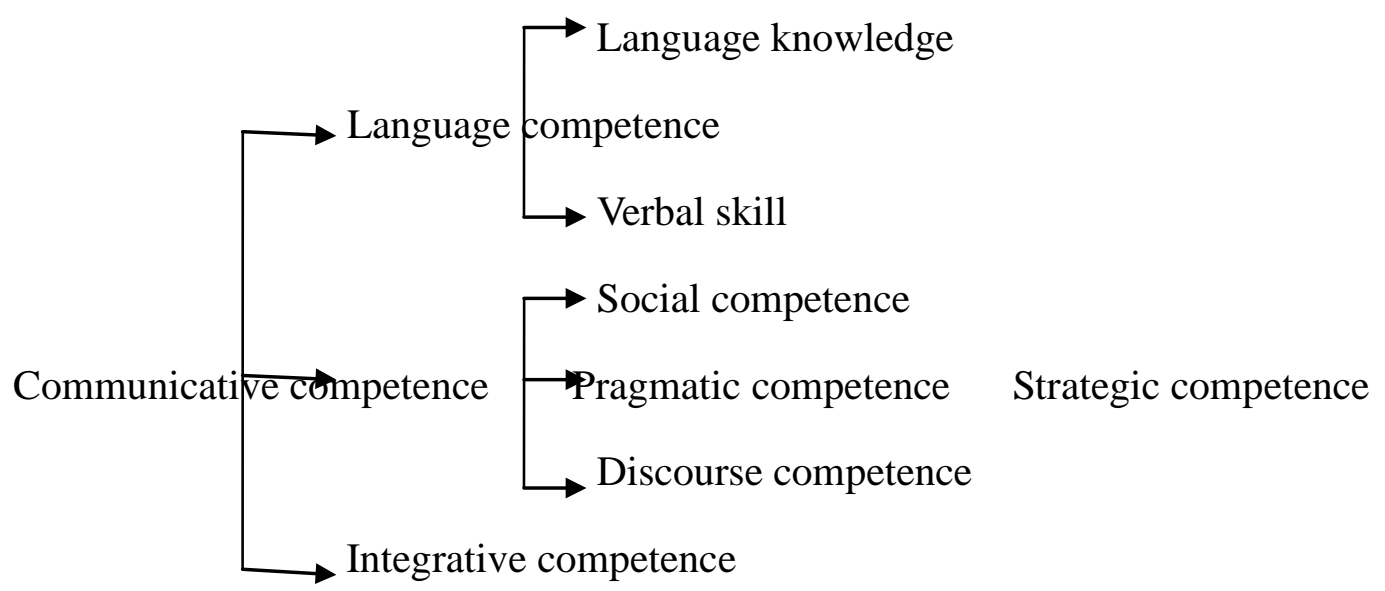

Pragmatic competence refers to the ability to use language for appropriate communication. Appropriateness is the highest principle for communication, whose meaning includes two aspects: on the one hand, viewed from pragmatic comprehension of second language learners, it refers to approaches used by second language learners to correctly understand intentions of speakers' verbal behaviors by virtue of certain context framework. This context framework includes common topic, discourse background and a set of logistical reasoning knowledge. On the other hand, viewed from pragmatic expression, it refers to the ability of second language learners to select appropriate discourse forms for communication in certain pragmatic occasions based on the time, place, condition, objective and target of discourse (Xu Siyi’s "pragmatic framework" theory in 1997, the "pragmatic occasion" theory in 2000).

Pragmatic competence is divided into two levels: language pragmatic competence and social pragmatic competence. Pragmatic competence refers to the ability of learners to accurately understand or appropriately express. It is a sort of extended grammatical competence, including the competence to correctly use grammatical rules for wording and phrasing and the competence to correctly use linguistic form, properly express semantics and accurately understand its functional significance in a certain context. Social pragmatic competence refers to the ability to perform 
appropriate communication by conforming to social rules for use of language. It is pragmatic competence at a higher level, and it involves social rules for use of language.

\section{Survey Design}

(I) Contents of survey

Only social pragmatic competence of overseas students is surveyed in this survey. This survey mainly involves the pragmatic rule acquisition of overseas students for salutations in three frequently experienced communicative contexts, the pragmatic appropriateness analysis in the implementation process of several verbal behaviors, and the pragmatic comprehension correctness analysis of some implications.

(II) Objects of survey

Objects of this survey are overseas students in Ningxia University. In total, 45 questionnaires are distributed, and 38 effective questionnaires are recovered. Basic information of surveyed objects is described as follows: from the perspective of sex, there are 18 boys and 18 girls respectively. From the perspective of language competence, there are 17 students in the advanced stage, accounting for $47.2 \%$ of the total number. There are 19 students in the middle stage, accounting for \% of the total number. With respect to nationality, survey objects are from 16 countries. 7 students are from Korea, accounting for 19\%. 5 students are from Egypt, accounting for 13.8\%. 5 students are from Sudan, accounting for 13.8\%. 4 students are from Kyrghyzstan, accounting for 11.1\%. 2 students are from Pakistan and Uzbekistan respectively, accounting for 5\% respectively. One student is from Iraq, Mauritania, Japan, Senegal, Kazakhstan, Australia, Yemen, USA and Laos respectively, according for $2.7 \%$ respectively.

(III) Questionnaire design

A survey and analysis is made onto second language pragmatic competence acquisition of second language learners with Chinese as the second language from three perspectives: salutation, individual verbal behavior and implication.

\section{Survey and Research on Pragmatic Competence Acquisition of Overseas Students for Salutation}

Chinese salutation reflects unique social cultural psychology of Chinese society, with complex classifications and wide varieties. Overseas students' acquisition of salutation is always a difficulty in foreign language teaching. In teaching practice, overseas students make many biased errors in the acquisition process of salutation due to inappropriate examples of salutation context, hysteretic nature of textbooks, or tolerance of teachers (or Chinese native speakers) for biased pragmatic errors of salutation. Overseas students initially arriving at China are frequently embarrassed by biased pragmatic errors of salutation, which influences overseas students' effects of Chinese communication and even attacks their confidence of using Chinese.

Three occasions frequently encountered by overseas students are set in this paper: asking for directions on campus, in the supermarket and in the restaurant. A survey and research is made on the situation of using salutation when overseas students are facing six different crowds of people (six different crowds of people are only distinguished from each other from the perspectives of age and sex).

Table 1 (1) Percentage of Using Different Salutations while Facing Six Different Crowds

\begin{tabular}{|c|c|c|c|c|c|c|}
\hline \multirow{2}{*}{} & \multicolumn{2}{|c|}{$\begin{array}{r}\text { Females in the Same } \\
\text { Seniority }\end{array}$} & \multicolumn{2}{c|}{$\begin{array}{r}\text { Males in the Same } \\
\text { Seniority }\end{array}$} & \multicolumn{2}{c|}{$\begin{array}{c}\text { Females in the Same } \\
\text { Seniority as Patents }\end{array}$} \\
\cline { 2 - 7 } & Appropriate & Inappropriate & Appropriate & Inappropriate & Appropriate & Inappropriate \\
\hline On campus & $23 / 63.9 \%$ & $13 / 36.1 \%$ & $25 / 69.4 \%$ & $11 / 30.6 \%$ & $27 / 75 \%$ & $9 / 25 \%$ \\
\hline In the & $10 / 27.8 \%$ & $26 / 72.2 \%$ & $13 / 36.1 \%$ & $23 / 63.9 \%$ & $16 / 44.4 \%$ & $20 / 55.6 \%$ \\
\hline
\end{tabular}




\begin{tabular}{|c|c|c|c|c|c|c|}
\hline supermarket & & & & & & \\
\hline $\begin{array}{c}\text { In the } \\
\text { restaurant }\end{array}$ & $30 / 83.3 \%$ & $6 / 16.7 \%$ & $30 / 83.3 \%$ & $6 / 16.7 \%$ & $29 / 80.6 \%$ & $7 / 19.4 \%$ \\
\hline Total & $63 / 58.3 \%$ & $45 / 41.7 \%$ & $68 / 63 \%$ & $40 / 37 \%$ & $72 / 66.7 \%$ & $36 / 33.3 \%$ \\
\hline
\end{tabular}

Table $1(2)$

\begin{tabular}{|c|c|c|c|c|c|c|}
\hline & \multicolumn{2}{|c|}{$\begin{array}{c}\text { Males in the Same } \\
\text { Seniority as Patents }\end{array}$} & \multicolumn{2}{c|}{$\begin{array}{c}\text { Females in the Same } \\
\text { Seniority as Grandfather }\end{array}$} & \multicolumn{2}{c|}{$\begin{array}{c}\text { Males in the Same } \\
\text { Seniority as Grandfather }\end{array}$} \\
\hline & Appropriate & Inappropriate & Appropriate & Inappropriate & Appropriate & Inappropriate \\
\hline On campus & $\begin{array}{c}28 / 77.8 \\
\%\end{array}$ & $8 / 22.2 \%$ & $8 / 22.2$ & $28 / 77.8$ & $11 / 30.6$ & $25 / 69.4$ \\
\hline $\begin{array}{c}\text { In the } \\
\text { supermarket }\end{array}$ & $23 / 63.9$ & $13 / 36.1$ & $12 / 33.3 \%$ & $24 / 66.7 \%$ & $5 / 13.9 \%$ & $\begin{array}{c}31 / 86.1 \% \\
\%\end{array}$ \\
\hline $\begin{array}{c}\text { In the } \\
\text { restaurant }\end{array}$ & $31 / 86.1$ & $5 / 13.9 \%$ & $19 / 52.8 \%$ & $17 / 47.2 \%$ & $20 / 55.6$ & $16 / 44.4$ \\
\hline Total & $82 / 75.9 \%$ & $26 / 24.1 \%$ & $39 / 36.1 \%$ & $69 / 63.9 \%$ & $36 / 33.3$ & $72 / 66.7 \%$ \\
\hline
\end{tabular}

Such several phenomena deserve our attention in Table 1 (1) and Table 1 (2) and the statistical process.

(I) Viewed from the three occasions:

1、 No matter in which age group, the percentage of appropriate salutations used by overseas students is the highest in the restaurant. This is greatly correlated with overseas students' early acquisition of the salutation "waiter" in the process of classroom teaching. This salutation is not only a vocational appellation but also a face-to-face term or a referral pronoun.

2、In the supermarket, special vocational salutation "salesclerk" is available. Moreover, overseas students learned about this word very early, and they know these people can be called "salesclerks". It is also used like this in dialogues in the textbook. With social development, however, this word is no longer used as a face-to-face term to call a salesman in the supermarket. Teachers fail to teach students this useful pragmatic information. In other words, overseas students fail to acquire the word "salesclerk" even through they learned about the word. This is the reason for low percentage of overseas students' using appropriate salutations in the supermarket. Such salutations gradually used as referral pronouns instead of face-to-face terms can be summarized, letting overseas students to acquire pragmatic competence while learning about such salutations.

(II) Viewed from overseas students facing crowds in different age groups:

For seniors in the same seniority as grandfather, the percentage of overseas students' using appropriate salutations is even lower than that of overseas students' using inappropriate salutations. This is associated with fewer descriptions on seniors in this age group in textbooks. Therefore, teachers seldom mention pragmatic knowledge in this aspect. It can be said that this is a blind point in the classroom teaching of pragmatics. In future practices, this should be paid attention to by Chinese teachers for foreigners.

: (III) Viewed from specific salutations selected by tested overseas students:

1、Young overseas students are very sensitive to relatively popular salutations. In the context of asking for directions on campus, a certain proportion of overseas students use "beautiful girl” or 
"handsome boy" to call persons in the same age.

2、 A certain proportion of overseas students have relatively strong salutation pragmatic competence. They acquired relevant pragmatic knowledge in natural contexts. In Chinese, for instance, we Chinese can directly say "hello" or "excuse me" when we are not sure about which salutation to use. Some overseas students act like this, and it is relatively appropriate.

In the three occasions of asking for directions (i.e. on campus, in the supermarket and in the restaurant), frequency statistical chi-square value and P value of "appropriate" and "inappropriate" salutations are listed in Table 2 when overseas students are facing six different crowds.

\begin{tabular}{|c|l|l|l|l|l|l|}
\hline & $\begin{array}{c}\text { Females in the } \\
\text { Same Seniority }\end{array}$ & $\begin{array}{c}\text { Males in the } \\
\text { Same Seniority }\end{array}$ & $\begin{array}{c}\text { Females in } \\
\text { the Same } \\
\text { Seniority as } \\
\text { Patents }\end{array}$ & $\begin{array}{c}\text { Males in the } \\
\text { Same } \\
\text { Seniority as } \\
\text { Patents }\end{array}$ & $\begin{array}{c}\text { Females in } \\
\text { the Same } \\
\text { Seniority as } \\
\text { Grandfather }\end{array}$ & $\begin{array}{c}\text { Males in the } \\
\text { Same } \\
\text { Seniority as } \\
\text { Grandfather }\end{array}$ \\
\hline$X^{2}$ & 23.543 & 18.185 & 12.250 & 4.964 & 7.465 & 14.250 \\
\hline P value & .000 & .000 & .002 & .084 & .024 & .001 \\
\hline
\end{tabular}

All $\mathrm{P}$ values of these items are less than 0.05 , with significant difference. It indicates that overseas students have already acquired pragmatic competence to use salutations for the six different crowds under the three occasions.

\section{Survey and Research on Overseas Students' Pragmatic Competence Acquisition in Individual Verbal Behaviors}

English is taken as the subject in most researches on the acquisition of several important verbal behaviors. However, researches on the acquisition of verbal behaviors with Chinese as second language are relatively insufficient. In this paper, relatively common verbal behaviors are selected for a simple analysis.

Among all options of each question, only one is the most appropriate. It is deemed as inappropriate for other options. Statistical results of "appropriate rate" and "inappropriate rate" are shown in Table 3.

\begin{tabular}{|c|c|c|c|}
\hline & Question No. & Appropriate & Inappropriate \\
\hline $\begin{array}{c}\text { Pragmatic perception } \\
\text { of personal pronoun }\end{array}$ & 1 and 2 & $19 / 26 \%$ & $53 / 73.6 \%$ \\
\hline $\begin{array}{c}\text { Answer to negative } \\
\text { question }\end{array}$ & 3 and 4 & $62 / 86 \%$ & $10 / 13.8 \%$ \\
\hline Euphemistic refusal & 5,6 and 12 & $61 / 56.4 \%$ & $47 / 43.5 \%$ \\
\hline $\begin{array}{c}\text { Complimentary } \\
\text { response }\end{array}$ & 7 and 10 & $43 / 59.7 \%$ & $29 / 40 \%$ \\
\hline Meeting and courtesy & 8 and 11 & $46 / 63.8 \%$ & $26 / 36.1 \%$ \\
\hline Farewell & 9 & $20 / 55.5 \%$ & $16 / 44.4 \%$ \\
\hline Total & 12 & $251 / 59.7 \%$ & $181 / 41.9 \%$ \\
\hline
\end{tabular}

For the table, we can draw a rough conclusion as follows:

1. Overseas students know little about pragmatic perception of personal pronouns, with the appropriateness statistical result as only $26 \%$. It can be seen that overseas students should continue to learn about necessary implications of pronouns in discourses in the middle and senior stages after mastering basic grammatical meanings of pronouns in the initial stage. In other words, teachers are 
about to transit to teaching and practice of pragmatic meanings of such pronouns. Thus, overseas students can really acquire Chinese pronouns.

2、 For answers to negative questions, $86 \%$ students influenced by transferring of their mother languages can select appropriate answers.

3、When "complimentary" verbal behaviors are involved, the inappropriate rate of Question 7 is very high (You commend your friend "your dress is very beautiful." "Thank you”, replied your friend. You should: A. Say "You're welcome”; B. Say "It should be”; C. Say nothing). When overseas students are replied as "Thank you" after commending others, they should select to say nothing. However, 75\% overseas students choose the answer "You're welcome". For Question 10 (after listening to your words, your friend commend "your Chinese is not bad". What you should say at this time? A. Indeed; B. You are talking nonsense; C. Just so-so), 96\% overseas students choose the modest answer "just so-so" conforming to social cultural psychology of Chinese people. It can be seen that overseas students master this pragmatic knowledge in the learning process. This is closely correlated with pragmatic teaching in class. Obvious trans-cultural pragmatic differences are generally noticed by people. For instance, euphemistic and implicit discourses also belong to obvious pragmatic differences. It is easy for overseas students to acquire such differences.

4、 Viewed from the total column of the table, overseas students' acquisition of verbal behavior pragmatic competence is not enough.

\section{Conclusion}

Due to limited contents of research, the author only made a survey in middle and advanced classes, so as to guarantee that tested overseas students can correctly understand the contents of this survey, and make relevant response. However, the number of tested overseas students fails to reach a more ideal quantity. The author expects to take this paper as an example and arouse attention and reflections of Chinese teachers for foreigners on the research on overseas students' Chinese pragmatic competence acquisition.

\section{Acknowledgements}

This paper is the scientific research funding project of Ningxia University: Survey and Research on Chinese Pragmatic Communicative Competence of Overseas Students in Ningxia (Project No.: SK1227).

\section{References:}

1、Xue Qiuning, 2005, Page 4 of the Survey on Overseas Students' Implementation of Chinese Request Verbal Behaviors and Acquisition Research;

2、Jiang Liping, 2007, Chinese Learning, Feb., 2007. 